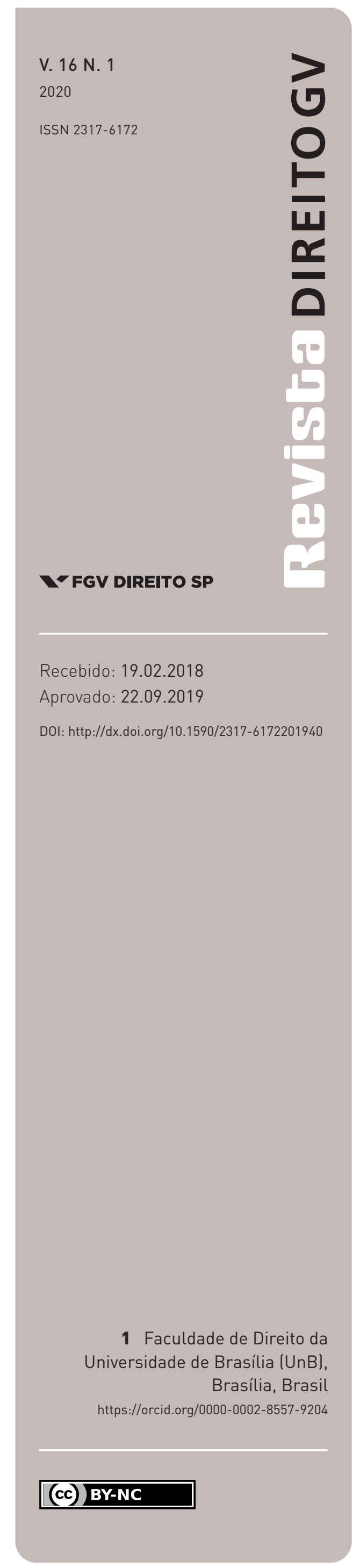

\section{Direito da concorrência e supermercados: como essas plataformas de dois lados podem trazer riscos aos consumidores?}

ANTITRUST LAW AND SUPERMARKETS: HOW THESE TWO-SIDED PLATFORMS CAN CAUSE HARM TO CONSUMERS?

Amanda Athayde ${ }^{1}$

\section{Resumo}

0 presente artigo propõe, à luz da evolução da tradicional visão antitruste dos supermercados varejistas, uma moderna análise antitruste do setor. Busca-se superar a ideia de que os supermercados figuram como agentes neutros de mercado, evidenciando que o poder de mercado no varejo supermercadista pode impactar negativamente na concorrência. Assim, o presente artigo estuda os supermercados como plataformas de dois lados com características de gargalo à concorrência. Nos termos da teoria da plataforma de dois lados, propõe-se que os supermercados sejam analisados como prestadores de serviços para consumidores finais e para os fornecedores, ressaltando que esses dois grupos distintos dependem do supermercado para o intermédio de transações, o que faz com que existam externalidades indiretas entre os dois grupos e, consequentemente, confere poder de barganha à plataforma. Por sua vez, nos termos da teoria dos gargalos à concorrência, defende-se que o supermercado varejista detém um poder monopolista de prover ou não o acesso de um grupo a outro. Tal proposta, como este artigo busca demonstrar, traz consigo um novo modo de compreensão das possíveis relações jurídicas dos agentes no varejo supermercadista, tanto em suas relações verticais quanto horizontais e diagonais.

\section{Palavras-chave}

Direito da concorrência; varejo supermercadista; plataforma de dois lados; teoria do gargalo à concorrência.

\begin{abstract}
This article proposes, in the light of the evolution of the traditional vision of retail supermarkets, a modern antitrust analysis of this sector, seeking to overcome the idea that supermarkets appear as neutral agents of the market, hence the market power in supermarket retailer can impact on the competition field. Thus, this article studies the supermarkets as two-sided platforms with characteristics of the competitive bottleneck. According to the two-sided platform theory, the supermarkets should be analyzed as service providers for final consumers and suppliers, noting that these two distinct groups depend on the supermarket for the intermediation of transactions, which means that there are indirect externalities between the two groups and, consequently, confers bargaining power to the platform. Furthermore, according to the theory of bottlenecks to competition, it can be argued that the retail supermarket has a monopoly power to provide access to one group or another. This proposal, as this article seeks to demonstrate, brings with it a new way of understanding the possible legal relationships of the agents in the retail supermarket, in their vertical, horizontal and diagonal relations.
\end{abstract}

\section{Keywords}

Antitrust law; supermarket retailer; two-sided platform; competitive bottleneck model. 


\section{INTRODUÇÃO}

Em janeiro de 2020, a rede varejista Walmart anunciou que passará não apenas a vender carnes em seus supermercados, mas também a atuar em toda a cadeia de processamento, desde o corte até a embalagem e a aposição da marca própria desses produtos. Trata-se de um movimento alinhado com outras experiências recentes nos Estados Unidos e em outros países do mundo, a partir do qual os supermercados saem de sua posição tradicional de revendedores e passam a assumir um papel mais ativo na cadeia de suprimentos de alimentos. Será que esse movimento traz benefícios aos consumidores? E, se trouxer, será que tais benefícios superam os eventuais riscos tanto aos consumidores quanto à concorrência no varejo supermercadista? Para responder a essa pergunta, deve-se inicialmente superar a tradicional visão do varejo supermercadista, outrora visto como um agente neutro no mercado, que simplesmente transmite a demanda do consumidor final aos fabricantes da indústria, e adotar uma moderna visão do varejo supermercadista, atentando-se para suas relações verticais, horizontais e diagonais no mercado.

O pressuposto dessa moderna análise antitruste dos supermercados é que é necessário levar em conta, além de preços, fatores como inovação, qualidade e variedade, a fim de criar e preservar o ambiente concorrencial e proteger o interesse da coletividade. Uma concorrência qualitativa resulta na redistribuição dos efeitos concorrenciais para os consumidores e para a sociedade, atingindo o fim último da justiça social apregoada na Constituição brasileira.

A visão tradicional coloca o varejo supermercadista como um agente/representante dos consumidores quando decide adquirir mercadorias dos fornecedores. Nesse sentido, entende-se que o varejista não tem poder de mercado ou, se o tem, exerce esse poder para o estrito benefício do consumidor final. Sob tal prisma, o exercício desse poder resultaria em menores preços de compra, que seriam repassados na forma de menores preços de venda no varejo, o que aumentaria a demanda do consumidor final sem restrição de oferta. Eventual tensão entre os fabricantes e os varejistas teria um resultado final neutro ou positivo para os consumidores finais. Sustenta tal visão tradicional que as autoridades de defesa da concorrência deveriam, portanto, se preocupar menos com o exercício do poder de mercado pela ótica da compra do que da venda, presumindo-se que pela primeira o poder de mercado seria utilizado como um mecanismo compensatório.

A análise antitruste tradicional aplica uma visão benéfica sobre o poder de compra ("buyer power"),

até mesmo em termos de nomenclatura. ${ }^{1}$ No varejo supermercadista, essa análise tradicional

1 Tem-se um tratamento diferenciado dado ao poder de mercado na compra (viés positivo) daquele na venda. Ao passo que o poder de mercado na venda é denominado genericamente poder de mercado ("market power"), o poder de mercado na compra é denominado especificamente poder de compra ("buyer power”), poder compensatório (“countervailing power”) ou poder de monopsônio (“monopsony power”). Essa 
pressupõe que os menores preços de compra resultantes do poder dos varejistas seriam totalmente repassados aos consumidores finais, significando maior output e bem-estar do consumidor. O poder de compra é visto como oriundo da habilidade de o varejista obter de seus fornecedores condições mais favoráveis do que aquelas disponíveis a outros compradores ou ao mercado em uma condição normal de competição. Esses termos mais favoráveis, por sua vez, dizem respeito tanto a preço quanto a condições contratuais que são relacionadas, por exemplo, a pagamento, qualidade, rotulagem, embalagem ou qualquer atividade de marketing/promoção.

Galbraith (1970) foi quem identificou pela primeira vez, ainda em 1952, as possibilidades de benefícios sociais associados ao poder compensatório. ${ }^{2}$ Para o autor, poder-se-ia gerar aumento de bem-estar por meio do poder compensatório, pois haveria o enfrentamento aos efeitos negativos do poder de mercado existente, bem como resultaria em ganhos que seriam repassados aos consumidores finais. ${ }^{3}$ Similarmente, Maitland-Walker (2000) sustenta que os grandes varejistas valer-se-iam do seu poder de compra para pressionar os fabricantes ao rebaixamento de preços ou a melhores condições de comercialização, que acabariam sendo revertidos ao consumidor. ${ }^{4}$

Especificamente sobre o varejo supermercadista, a análise tradicional indica que os possíveis efeitos negativos do poder de compra ao bem-estar do consumidor surgiriam apenas em situações bastante restritas. No mercado varejista (“output market”), ${ }^{\mathbf{5}}$ tais efeitos negativos

diferença de nomenclatura é observada, por exemplo, na medida em que, por um lado, para avaliar o poder de mercado de um fabricante (vendedor) de produtos, a linguagem utilizada é simplesmente de poder de mercado, sem se definir que é o poder de mercado na venda. Por outro lado, para avaliar o poder de mercado de um distribuidor (atacadista/varejista) na compra, o termo utilizado não é o do poder de mercado, mas sim a nomenclatura específica do poder de compra ou do poder de barganha, em contraposição implícita ao poder dos fabricantes (poder compensatório). Essa diferenciação, por sua vez, leva a diversas tentativas de delimitação e aprofundamento sobre o conceito de poder de compra e sobre suas relações jurídicas, em contraposição à reconhecida - ainda que não necessariamente pacífica - definição do conceito de poder de mercado na venda.

2 Sob o prisma da demanda, a união de compradores, seja via associações de compra, seja via fusões, seria um novo mecanismo "autorregulador" do mercado, pois equilibraria forças com os fornecedores.

3 A tese de Galbraith foi e continua sendo contestada na definição de como os ganhos derivados do poder de compra seriam repassados para os consumidores. Um dos primeiros críticos a essa tese foi Whitney (1953).

4 Ainda, segundo o autor, o desenvolvimento de marcas próprias resultaria na comercialização de produtos a preços mais convenientes aos consumidores, e essa maior diversidade de produtos nas gôndolas representaria mais opções aos consumidores, que se beneficiariam da concorrência entre os produtos. Assim, a realização de guerras de preços e promoções entre os varejistas seria benéfica ao bem-estar do consumidor.

5 O termo "mercado varejista" será utilizado para referir-se ao mercado pela ótica da venda, cujas expressões em inglês são "output market” ou “downstream market”. Essa expressão é normalmente empregada como contraponto 
seriam observados unicamente se o menor preço de compra obtido por um varejista resultasse na saída de outros concorrentes do mercado ou no aumento de preços a outros varejistas. Por sua vez, no mercado de aprovisionamento ("input market"), os efeitos negativos apenas apareceriam nas hipóteses restritas de saída dos fabricantes do mercado ou de redução de seus investimentos a ponto de aumentar os preços de venda ao consumidor. É dada preferência, pela ótica tradicional, aos benefícios estáticos de curto prazo relacionados a preço, sem levar necessariamente em conta os efeitos dinâmicos de médio e longo prazo na concorrência no mercado, tais como os relacionados a qualidade, inovação e variedade.

Berasategi (2014) discute que esse tipo de análise negligencia evidências do exercício de poder de mercado pelos varejistas e que, com base nesses argumentos tradicionais, as autoridades de concorrência estariam restringindo sua atuação no setor do varejo supermercadista (por vezes denominado "varejo alimentar") a atos de concentração econômica ou a tarefas de advocacia da concorrência, sem se adentrar na análise de eventuais condutas anticompetitivas praticadas nesse mercado. Tal restrição apontada pelo autor é realidade no Brasil. A normativa ${ }^{\mathbf{6} 7}$ e a jurisprudência administrativas brasileira a respeito do poder de compra (e, consequentemente, no poder de compra no varejo supermercadista) praticamente se restringem aos atos de concentração, e parecem se alinhar à visão tradicional. Mesmo nas operações de concentração econômica nas quais se esboçou alguma preocupação em relação ao poder de compra no Brasil, a

ao termo "mercado de aprovisionamento", que se refere ao mercado pela ótica da compra dos supermercados - em que os fabricantes realizam suas vendas. Esse termo reflete as expressões em inglês "input market" e "upstream market”.

6 O Guia de Análise Econômica dos Atos de Concentração Horizontal das Secretarias de Acompanhamento Econômico (doravante "Seae") e de Direito Econômico (doravante "SDE”) encampava a visão, ainda que implícita, de que o poder de compra, como poder compensatório, seria positivo para a concorrência, tratado como uma eficiência da operação (BRASIL, 2001). No parágrafo 74, que trata da análise das eficiências econômicas resultantes da operação, aponta-se que pode ser considerada eficiência específica da operação a geração de um poder de mercado compensatório. Esse posicionamento também parece ser adotado, por exemplo, nos Guias de Restrições Verticais e de Acordos Anticoncorrenciais da União Europeia, em que o poder de compra é sinalizado sob o viés positivo. O Guia de Análise de Restrições Verticais da União Europeia avança um pouco ao mencionar, no capítulo relativo aos acordos de gestão de categoria, a possibilidade de fechamento de mercado aos fabricantes detentores de marcas independentes em decorrência das práticas dos supermercados detentores de poder de compra relacionadas a acesso às lojas (COMISSÃO EUROPEIA, 2010a). Ainda na União Europeia, o Guia de Acordos Anticoncorrenciais da União Europeia associa o termo "consumidor" ao termo "distribuidor" (atacadista/varejista), implicitamente considerando-o como um intermediário neutro no mercado (COMISSÃO EUROPEIA, 2004).

7 O Guia de Análise dos Atos de Concentração Horizontal (“doravante Guia H”) ainda corrobora essa visão tradicional, em que pese dar um passo adiante e mostrar atenção ao tema do poder de compra, com um capítulo específico subdividido entre poder compensatório e poder de monopsônio (BRASIL, 2016). 
análise realizada não foi aprofundada. ${ }^{8}$ Ademais, não há processo administrativo instaurado ou julgado pelo Plenário do Cade que avalie com profundidade as preocupações concorrenciais com as práticas comerciais horizontais ou verticais praticadas por supermercados. ${ }^{9}$ Em que pese terem sido realizadas algumas poucas investigações preliminares, estas não prosseguiram sob o argumento de supostamente serem relações privadas, que não caracterizariam infração à ordem econômica.

Ao contrário do que se observa no Brasil, no exterior a análise tradicional centrada nos efeitos estáticos de curto prazo relacionados a preço vem sendo superada por estudos de autoridades antitruste estrangeiras, organismos internacionais e acadêmicos, que aportam evidências práticas para a mudança de paradigma.

Propõe-se, nesse sentido, que os supermercados sejam analisados concorrencialmente como plataformas de dois lados, com características de gargalo à concorrência ("gatekeeper"), como prestadores de serviços para consumidores finais e para fornecedores. Essa proposta traz consigo um novo modo de compreensão das possíveis relações jurídicas dos agentes no varejo supermercadista, tanto em suas relações verticais quanto horizontais, movimento necessário para alcançar a análise qualitativa da concorrência, superando a ultrapassada visão da concorrência apenas como disputa por preço.

A aplicação dessa nova compreensão do varejo supermercadista ao contexto brasileiro tem relevância jurídica ao propor uma análise que observe o varejista como um agente de

8 Os principais motivos para levarem essa constatação pelos autores seriam: foco das análises na oferta, em detrimento da avaliação sobre a demanda (compra); participação na compra era considerada insuficiente para causar danos sobre o mercado; desnecessidade de avaliação dos efeitos do poder de compra quando comprovado o cartel; e celebração de Termo de Cessação de Conduta que resulta no arquivamento do caso sem aprofundamento sobre o tema (RAGAZZO e MACHADO, 2013).

9 Essa informação também é corroborada pelas pesquisas de casos realizadas por Berardo e Becker (2015, p. 95-106). "In the grocery sector, however, there is no record of a decision or even an investigation for any type of horizontal conduct, such as collective boycotts or price-fixing practices. No investigation of cases involving joint retaliation from suppliers, especially small-sized ones, has actually taken place, at least publicly". "There have been no precedents recommended resale prices in the retail grocery sector. The CADE, however, has recently condemned a company for resale price fixing [SKF Brasil Ltda., Administrative Proceeding n. 08012.001271 /2001-44]". "The CADE has never, however, found an infringement of the competition law on the basis of an abuse of buying power. [...] In the past, several cases have dealt with dependency, but the CADE highlighted that dependency, i.e. one seller depending exclusively or almost exclusively on purchases made by one purchaser, does not in itself necessarily correspond to buying power, which obviously depends on aggregate market output and purchases. Nonetheless, there is no precedent regarding infringements involving buying power or dependency. There have been a number of dependency cases in the early 2000s that superficially discuss the manufacturer-distributor relationship. These cases discuss the extent to which the private relation should be governed by competition law and state that it the plaintiff cannot show harm or potential harm to competition (as opposed to private harm to a single distributor), it should not be subject to the CADE's analysis. At the same time, there has been no case of 'waterbed effect' related to retailers in Brazil'. 
mercado que pode influenciar nas variáveis preço, qualidade e quantidade ofertada dos produtos comercializados e, consequentemente, no bem-estar do consumidor.

Como forma de explicar essa proposta, o presente artigo se dividirá nos seguintes tópicos: (1) breve exposição da teoria da plataforma de dois lados, explicando a ideia das empresas que atendem, simultaneamente, dois grupos interdependentes de adquirentes para, a partir disso, (2) caracterizar os supermercados como plataformas de dois lados, visto que prestam serviços para consumidores finais e fornecedores, grupos interdependentes entre si. Após, analisaremos (3) a teoria do "gargalo à concorrência" e como ela se aplica ao supermercado como plataforma de dois lados, para, com base nesses estudos, verificarmos (4) as relações jurídicas do varejo supermercadista e os novos paradigmas dessas relações.

\section{BREVE TEORIA DA PLATAFORMA DE DOIS LADOS}

A teoria da plataforma de dois lados tem como alguns de seus principais autores Rochet e Tirole (2002, 2003, 2004 e 2006), Evans (2003a e 2003b), Parker e Van Alstayne (2005), Caillaud e Jullien (2001 e 2003), Armstrong (2006) e Schmalensee (2016). A expressão, oriunda do inglês "two-sided platforms", foi usada inicialmente por Rochet e Tirole (2004) para se referir a situações em que as empresas atendem, simultaneamente, dois grupos interdependentes de adquirentes. Para os autores, a plataforma pode afetar o volume de transações ao cobrar mais de um lado do mercado e reduzir o preço pago do outro lado na mesma proporção. Ou seja, haveria uma adaptação da estrutura de preço (LLANES e RUIZ-ALISEDA, 2015), sob a presunção de manutenção do "price level" geral. Um dos lados da plataforma, portanto, subsidiaria o negócio do outro lado ("loss leader") (ROCHET e TIROLE, 2006). Segundo os autores, a plataforma existiria, então, quando houvesse (i) dois grupos distintos que precisam interagir um com o outro e (ii) externalidades indiretas positivas entre esses dois grupos de consumidores.

Por sua vez, Evans (2003a) usa o conceito de plataforma de dois lados para se referir genericamente a situações em que existem dois grupos de consumidores que se beneficiam da interação e para quem a plataforma pode oferecer uma intermediação eficiente de serviços. Assim, seriam condições para uma plataforma de dois lados: (i) dois ou mais grupos distintos de consumidores; (ii) externalidades associadas ao fato de dois ou mais grupos estarem conectados ou coordenados de algum modo; e (iii) um intermediário que internalize as externalidades criadas por um grupo ao outro grupo.

Ainda, Weyl (2008) adota uma definição mais flexível, segundo a qual mercados de dois lados seriam modelos de comportamentos de empresas em que a interdependência entre eles se mostra uma importante ferramenta de análise. Em termos de interdependência, a plataforma precisa que os dois grupos estejam “a bordo” para propriamente operar, uma vez que, sem um lado da plataforma, o outro lado não aderiria. Em termos simples, um mercado de dois lados seria aquele em que uma empresa vende produtos ou presta serviços distintos a dois grupos diferentes de consumidores, e reconhece que vender mais para um grupo afeta 
a demanda do outro, e vice-versa (FILISTRUCCHI, GERADIN eVAN DAMME, 2012). Geralmente, esses grupos - ou um deles - não conseguem obter o mesmo valor, ou pelo menos não conseguem obtê-lo na mesma extensão, sem se utilizarem da plataforma. É nesse sentido que Caillaud e Jullien (2003) definem essa situação como o problema da "galinha e do ovo", pois, para atrair compradores, o intermediário deve ter uma grande base de vendedores, porém, para que os vendedores possam aderir à plataforma, é necessário ter, no mínimo, expectativa de que há ou haverá compradores do outro lado.

Filistrucchi, Geradin e Van Damme (2012), após analisarem as definições da literatura, apontam para as seguintes características identificadoras dos mercados de dois lados: (i) a existência de uma empresa intermediadora que vende mais de um produto ou serviço; (ii) a presença de dois grupos distintos, cada um comprando diferentes produtos ou serviços; e (iii) a interdependência entre as demandas e a ausência de completa transferência dos benefícios (“pass-through") entre os grupos no caso de transações no mercado.

Finalmente, Hagiu (2007) alerta no sentido de que há uma miríade de cenários entre os dois extremos que caracterizam uma relação de compra e venda simples e uma plataforma de dois lados. A caracterização de um intermediário como plataforma de dois lados, portanto, estaria menos ligada à natureza da plataforma e mais ligada às decisões que são tomadas pelas empresas que dela fazem parte. É por esse motivo que Rysman (2009) propõe a utilização da expressão "estratégias de dois lados" em vez de "mercados de dois lados".

A Organização para a Cooperação e Desenvolvimento Econômico (OCDE) (2009), com fundamento na doutrina e na experiência das autoridades antitruste ao redor do mundo, realizou amplo estudo em 2009 sobre essa teoria e apontou que não há uma definição universalmente aceita para o conceito de "mercado de dois lados". Existiria, porém, um consenso a respeito dos três aspectos fundamentais que caracterizariam uma plataforma de dois lados: (i) a existência de dois grupos distintos, que precisam um do outro de alguma maneira e que confiam na plataforma para intermediar as transações entre eles, sendo a plataforma o provedor de produtos e/ou serviços simultaneamente; (ii) a existência de externalidades indiretas ${ }^{\mathbf{1 0}}$

10 Segundo a $\operatorname{OCDE}(2017$, p. 3, tradução nossa), os efeitos de rede, quando considerados em mercados de vários lados, "são as externalidades entre plataformas ocorridas quando resultam das ações dos participantes em qualquer lado da plataforma, ou da plataforma em si mesma, afetando participantes dos outros lados da plataforma (ou da plataforma em funcionamento em si mesma). Essas externalidades podem ser diretas - como quando um aumento de provedores de conteúdo torna a plataforma mais cara aos consumidores de conteúdo -, ou indiretas - como quando uma melhora qualitativa aos usuários torna a plataforma mais atrativa aos provedores de conteúdo ou serviços e para anunciantes". Assim como no paper da OCDE, este artigo tratará as externalidades entre plataformas simplesmente como "efeitos de rede". A respeito da diferença entre externalidades diretas e indiretas: "Direct Network effects arise when the value of a good to a consumer increases directly with the number of people using that good. Telephony services are more valuable for a given consumer, the larger the number of other consumers that also use them, because he can communicate with 
entre os grupos de adquirentes, de modo que o valor que um dos lados da plataforma atribui a ela aumenta o número do outro lado da plataforma; e (iii) a não neutralidade da estrutura de preço, ou seja, a plataforma afeta o volume das transações - por exemplo, aumentando os preços de um lado para diminuir do outro e induzindo ambos a aderir à plataforma -, não sendo um intermediário neutro no mercado.

Ademais, a OCDE sinaliza a necessidade de se considerarem ambos os lados na definição e na análise concorrencial dos mercados relevantes. Sugere-se a superação dos métodos de análise tradicionais e das fórmulas aplicáveis a análises de mercados de um lado, como o teste do monopolista hipotético. Estes, segundo se indica, não se aplicariam aos mercados de dois lados, a não ser que fossem reformulados/adaptados (WRIGHT, 2004). Algumas condutas anticompetitivas que poderiam surgir no bojo de plataformas de dois lados, relacionadas a preço - como preços predatórios ou excessivos -, deveriam considerar os níveis de preços somando os praticados em ambos os lados da plataforma, e não os preços individuais ou a estrutura de preços separadamente. Por sua vez, condutas não relacionadas a preço - como acordos de exclusividade e venda casada - estariam no centro das discussões antitruste, pelos riscos de limitação da concorrência e do fechamento de mercado para rivais. Nesses casos, a análise deveria considerar como a conduta em um lado da plataforma afeta o outro lado do mercado, bem como o efeito geral da prática para o bem-estar da sociedade.

O compilado da OCDE também indica que algumas atividades econômicas foram consideradas plataformas de dois lados pelas autoridades antitruste ao redor do mundo, sendo objeto de análise concorrencial e/ou de remédios concorrenciais e/ou regulatórios por autoridades. Entre elas, citam-se as seguintes: sistemas operacionais de computador (intermedeiam desenvolvedores de software e usuários de computador); sistemas informatizados de reserva ("computerized reservation systems"); ${ }^{11}$ cartões de crédito (intermedeiam possuidores de cartões e comerciantes) (“card payment networks"); ${ }^{12}$ corretagem imobiliária (intermedeia

more people. Indirect Network effects arise when the value of a good to a consumer increases with the number of people using that good, but only indirectly" (OCDE, 2009, p. 29). Nos termos de LIM (2015), a diferença estaria no fato de que as externalidades diretas seriam encontradas dentro do grupo ("within"), ao passo que as externalidades indiretas seriam encontradas entre os grupos (“between”).

11 Sobre o mercado de sistemas informatizados de reserva (“computerized reservation systems") como plataforma de dois lados, ver: Europa (1989, revogada em 2009). Council Regulation 2299/1989, de 24.07.1989, subsequentemente emendada pelas Regulations 3089/1993 e 323/1999. Essa regulamentação setorial foi recentemente revogada pela Regulation 80/2009 of the European Parliament and of the Council of 14 January 2009 on a Code of Conduct for computerized reservation systems.

12 Sobre o mercado de redes de pagamento por cartão ("card payment networks") como plataforma de dois lados, Europa e Estados Unidos intervieram para suprimir ou reduzir as restrições impostas. Na Europa (2012), inclusive, foi proposta uma regulamentação dos pagamentos nesse mercado na Commission Green Paper, "Towards an integrated European market for card, internet and mobile payments", COM/2011/0941 final, 
inquilinos e proprietários); provedores de serviço de internet ("internet service providers"); ${ }^{13}$ portais de internet e sistemas de busca (intermedeiam sites e internautas) ("internet search engines") $;^{14}$ registro de nome de domínio na internet ("internet domain name registration"), ${ }^{15}$ plataformas de mídia ("media platforms"), ${ }^{16}$ redes de comunicação móveis ("mobile communications networks"), ${ }^{17}$ revistas (intermedeiam leitores e escritores); páginas amarelas (intermedeiam leitores e empresas); shoppings (intermedeiam lojas e compradores), softwares de publicação (intermedeiam autores e leitores), consoles de videogame (intermedeiam jogadores e desenvolvedores), mercados de reposição de peças (“aftermarkets"); ${ }^{18}$ bem como vários tipos

11.01.2012, Proposal for a Regulation of the European Parliament and of the Council on interchange fees for card-based payment transactions, COM/2013/5503, 24.07.2013.

13 Sobre o mercado de provedores de serviço de internet ("internet service providers") como plataforma de dois lados, observa-se a tentativa da Comissão Europeia de expressamente regular a denominada "neutralidade das redes" no European Parliament Resolution of 17 November 2011 on the open internet and net neutrality in Europe, P7_TA-PROV(2011)0511 and Connected Continent legislative package. Por sua vez, nos Estados Unidos (2010) também há a imposição da neutralidade das redes.

14 Sobre o mercado de sites de busca na internet ("internet search engines") como plataforma de dois lados, existe investigação sobre práticas do Google na Europa (COMISSÃO EUROPEIA, 2010b e 2013a) e também no Brasil (onde há três casos instaurados para investigar conduta anticompetitiva do Google nesse mercado: o Processo Administrativo 08700.009082/2013-03, que investiga conduta de screping; o Processo Administrativo 08700.010483/2011-94, que investiga a conduta de search bias e de restrições de anúncios com foto, em detrimento de sites de comparação de preço; e o Processo Administrativo 08700.005694/2013-19, que investiga restrições à interoperabilidade entre plataformas de busca patrocinada que o Google teria imposto por meio dos Termos e Condições da API do AdWords).

15 Sobre o mercado de registro de nome de domínio na internet ("internet domain name registration") como plataforma de dois lados, houve discussão nos Estados Unidos e na Europa sobre a eficiência ou não da proibição da Internet Corporation for Assigned Names and Numbers (ICANN) sobre os riscos concorrenciais da integração vertical das atividades de registro.

16 Sobre o mercado de plataformas de mídia ("media platforms") como plataforma de dois lados, autoridades de concorrência consideram que as empresas que fazem propaganda na plataforma de mídia estão em posição igualitária em comparação com os usuários que leem, escutam ou visualizam a plataforma. No Canadá, inclusive, para a aprovação da fusão entre Carlton/Granada, foram impostas regras de proteção contra práticas desleais e discriminatórias.

17 Sobre o mercado de redes de comunicação móveis (“mobile communications networks") como plataforma de dois lados: Europa. Regulation 531/2012 of the European Parliament and of the Council of 13 June 2012, on roaming on public mobile communication networks within the Union, que revogou a legislação anterior, Regulation 717/2007 of the European Parliament and of the Council of 27 June 2007, on public mobile telephone networks within the Community and amending Directive 2002/21 /EC.

18 Sobre os mercados de reposição de peças (“aftermarkets”) como plataforma de dois lados, na Europa já se determinou, no mercado automotivo especificamente, a obrigação de acesso não discriminatório a oficinas por parte das fabricantes de peças automotivas para reposição. 
de serviços de intermediação, como agências de correspondência e de emprego, casas de leilão, redes de vouchers de serviços, sistemas de pagamento, alguns sistemas de telecomunicações, publicações científicas, das redes de pagamento por cartão. Evans e Schmalensee (2016) indicam algumas das "multisided platforms" mais recentes, como Facebook, Visa, Open Table, Airbnb, Uber, etc., e descrevem seu modo de funcionamento e sucesso.

\section{SUPERMERCADOS COMO PLATAFORMAS DE DOIS LADOS: PRESTADORES DE SERVIÇOS} PARA CONSUMIDORES FINAIS E PARA FORNECEDORES

Acadêmicos como Armstrong (2006 e 2007) e Berasategi (2014), bem como autoridades antitruste estrangeiras, como o Tribunal Vasco de Defensa de la Competencia (2009), a Autoridade Russa de Concorrência (OCDE, 2009, p. 201), a Comissão Europeia (2010c), o documento para discussão da United Nations Conference on Trade and Development (UNCTAD) (2014) e o documento da OCDE (2018), sinalizam no sentido de caracterizar os supermercados como plataformas de dois lados. Similarmente, propõe-se neste artigo que se tenham os supermercados como plataformas de dois lados nas análises concorrenciais, pois preenchem as três características fundamentais desse conceito: (i) a existência de dois grupos distintos que precisam um do outro de alguma maneira e que confiam na plataforma para intermediar as transações entre eles; (ii) a existência de externalidades indiretas entre os grupos de consumidores; e (iii) a não neutralidade da estrutura de preço.

Quanto à característica (i) de fornecer produtos e/ou serviços simultaneamente para dois grupos distintos que precisam um do outro de alguma maneira e que confiam na plataforma para intermediar as transações entre eles, verifica-se que os supermercados prestam serviços a dois grupos: os consumidores finais e os fornecedores de marcas independentes. Ambos precisam uns dos outros - os consumidores precisam dos produtos e os fabricantes precisam escoar sua produção de produtos de marca independente no mercado -, de modo que o supermercado intermedeia um e outro.

De um lado da plataforma, o supermercado presta serviços aos consumidores finais consistentes na disponibilização de produtos no modelo de negócios one-stop shopping. Esse modo de fazer compras influenciou a mudança no padrão de compra dos consumidores, pois permite realizá-las em um só local, com maior variedade de produtos. Também possibilita comparar preços, obter economias de custos e ganho de tempo (por exemplo, decorrente da intensificação do trânsito), evitar riscos com a inflação e usufruir de estacionamento gratuito, entre outras facilidades (FORGIONI, 2008, p. 573). A maior ou menor valorização do modelo one-stop stopping pelos consumidores varia de acordo com fatores como tempo, acesso a transporte e habilidade de estocar itens perecíveis até a próxima ida aos supermercados. Assim, mesmo oferecendo esse modelo one-stop shopping, nenhum supermercado disponibiliza aos consumidores exatamente a mesma experiência de compra, pois esta resulta da combinação de fatores como localização, preços, seleção (pluralidade de 
produtos), qualidade e outras variáveis que afetam a escolha do consumidor (BASKER e NOEL, 2013).

Do outro lado da plataforma, o supermercado presta serviços aos fornecedores de marcas independentes. Essa prestação de serviços está relacionada ao acesso à loja e também aos serviços dentro desta, "access to and competition within supermarket platform" (BERASATEGI, 2014). O preço cobrado pelos supermercados de seus fornecedores é, então, uma tarifa bipartite, exigida não apenas por aderir à plataforma, mas também por usá-la, nos termos de Filistrucchi, Geradin e Van Damme (2012). Esses fornecedores apenas atingirão os consumidores - ou apenas os alcançarão na mesma extensão - se intermediados pela plataforma dos supermercados.

Assim, essa intermediação de transações realizada pelos supermercados a ambos os lados da plataforma, com as demais características a seguir mencionadas, os qualifica como plataforma de dois lados, por seu papel de prestador de serviços one-stop shopping aos consumidores e também de prestador de serviços de acesso à e dentro da plataforma aos fornecedores.

Quanto à característica (ii) de existirem externalidades indiretas entre os grupos, tem-se que o valor que um grupo atribui à plataforma de um lado aumenta o número de consumidores do outro lado. Por um lado, verifica-se que os consumidores finais valorizam o supermercado pelo modelo de negócios one-stop shopping, que reúne variedade e conforto em uma única localidade, consistente em uma das explicações da emergência global dos supermercados (RICHARDS e HAMILTON, 2012). Por outro lado, os fabricantes fornecedores valorizam os supermercados pela habilidade de atrair a maior quantidade possível de clientes, e o maior número de consumidores finais em uma cadeia de supermercados tende a atrair o fornecimento por parte de mais fabricantes de produtos de marca independente (VIANNINI, 2008). Assim, quanto maior seu alcance junto aos consumidores finais, maior o poder dos supermercados perante seus fornecedores (GORDILHO JR., 2012, p. 51). Essas externalidades indiretas promovidas pelos varejistas, com as demais características supra e inframencionadas, os qualificam como plataforma de dois lados, pelo valor dado ao one-stop shopping pelos consumidores e pelas repercussões geométricas de atração de fornecedores.

Finalmente, quanto à característica (iii) da estrutura de preço da plataforma afetar a dimensão das transações, os supermercados alteram a estrutura de preços dos fornecedores aos consumidores finais. Os varejistas tendem a cobrar dos consumidores finais menores preços para enfrentar a concorrência horizontal a jusante. Ao mesmo tempo, porém, tendem a cobrar dos fornecedores taxas e condições de acesso cada vez mais altas, bem como exigir o cumprimento de cláusulas/práticas que aumentam sua rentabilidade. O supermercado atua, então, como um intermediário não neutro no mercado, que altera a estrutura de preços ao longo da plataforma, possuindo a capacidade de defini-los em praticamente ambos os lados (ARMSTRONG, 2007). A análise passa a ter contornos ainda mais cinzentos ao se levar em conta o crescimento das marcas próprias, que concorrem com os produtos das marcas independentes dos fornecedores e que podem suscitar alterações ainda mais significativas na 
estrutura de preços na plataforma. Essa diferenciação na estrutura de preços realizada pelos supermercados a ambos os lados da plataforma, junto com as demais características supramencionadas, os qualifica como plataforma de dois lados, em que os preços menores obtidos pelos supermercados na compra de produtos nem sempre são repassados para os consumidores. Nesse sentido, quanto menor a taxa de transferência dos benefícios, mais importante é a natureza da plataforma como de dois lados (FILISTRUCCHI, GERADIN e VAN DAMME, 2012, p. 10).

A evidência de ser o supermercado uma plataforma de dois lados torna os instrumentos tradicionais da análise antitruste inválidos ou, no mínimo, demandantes de reformulação. A visão tradicional dos supermercados como agentes neutros de mercado evolui e dá lugar a um novo paradigma, em que os serviços oferecidos pelos supermercados transcendem a uma relação comercial ${ }^{19}$ e devem ser vistos sob a ótica dos dois mercados da plataforma.

\section{Plataforma De dois lados Com Características De “Gargalo À CONCORRÊNCia”}

\section{I. BREVE TEORIA DO “GARGALO À CONCORRÊNCIA” (“COMPETITIVE BOTTLENECK MODEL” "“GATEKEEPER”)} A teoria do gargalo à concorrência (competitive bottleneck model) foi desenvolvida inicialmente por Armstrong (2006) em seu artigo sobre plataformas de dois lados que servem a dois grupos diferentes de consumidores. Segundo essa teoria, enquanto um primeiro grupo tem acesso a diversas plataformas (multi-home), um segundo tem acesso apenas a uma plataforma (single-home). O primeiro grupo, que costuma ser dos vendedores, só consegue acessar o segundo grupo, que tende a ser dos compradores, por meio da plataforma escolhida pelo grupo single-home. A plataforma passa, então, a deter o poder monopolista de prover ou não acesso dos multi-home aos single-home. A plataforma se torna, dessa maneira, um competitive bottleneck, ou seja, um gargalo à concorrência, que pode cobrar e explorar o primeiro grupo (multi-home) para o benefício - ou não - do segundo grupo (single-home).

19 Alguns dos exemplos que justificam a afirmação de que a relação entre supermercados e fornecedores transcende a uma mera relação comercial e passa a ser de intermediação na base de uma plataforma de dois lados. Em um primeiro exemplo, os supermercados alugam espaço em gôndola para os fornecedores, sem necessariamente passar a deter a propriedade dos bens que distribuem. Em outro exemplo, os supermercados começam a alocar produtos de marca própria e de marcas independentes com base em fatores variados, que não apenas preço. Em um terceiro exemplo, os supermercados, além de comprarem os produtos dos fornecedores de marcas independentes após uma negociação bilateral, oferecem outros serviços remunerados, o que faz que a escolha do produto do fornecedor pelo supermercado vá além do preço de compra do produto, e leve em conta - principalmente, a nosso ver - os outros serviços que são por ele prestados e a ele remunerados ("serviços de acesso", que podem incluir serviços logísticos, serviços de "listagem”, serviços dentro da loja). 
A Figura 1, a seguir, ilustra um gargalo à concorrência.

\section{FIGURA 1 - GARGALO À CONCORRÊNCIA}

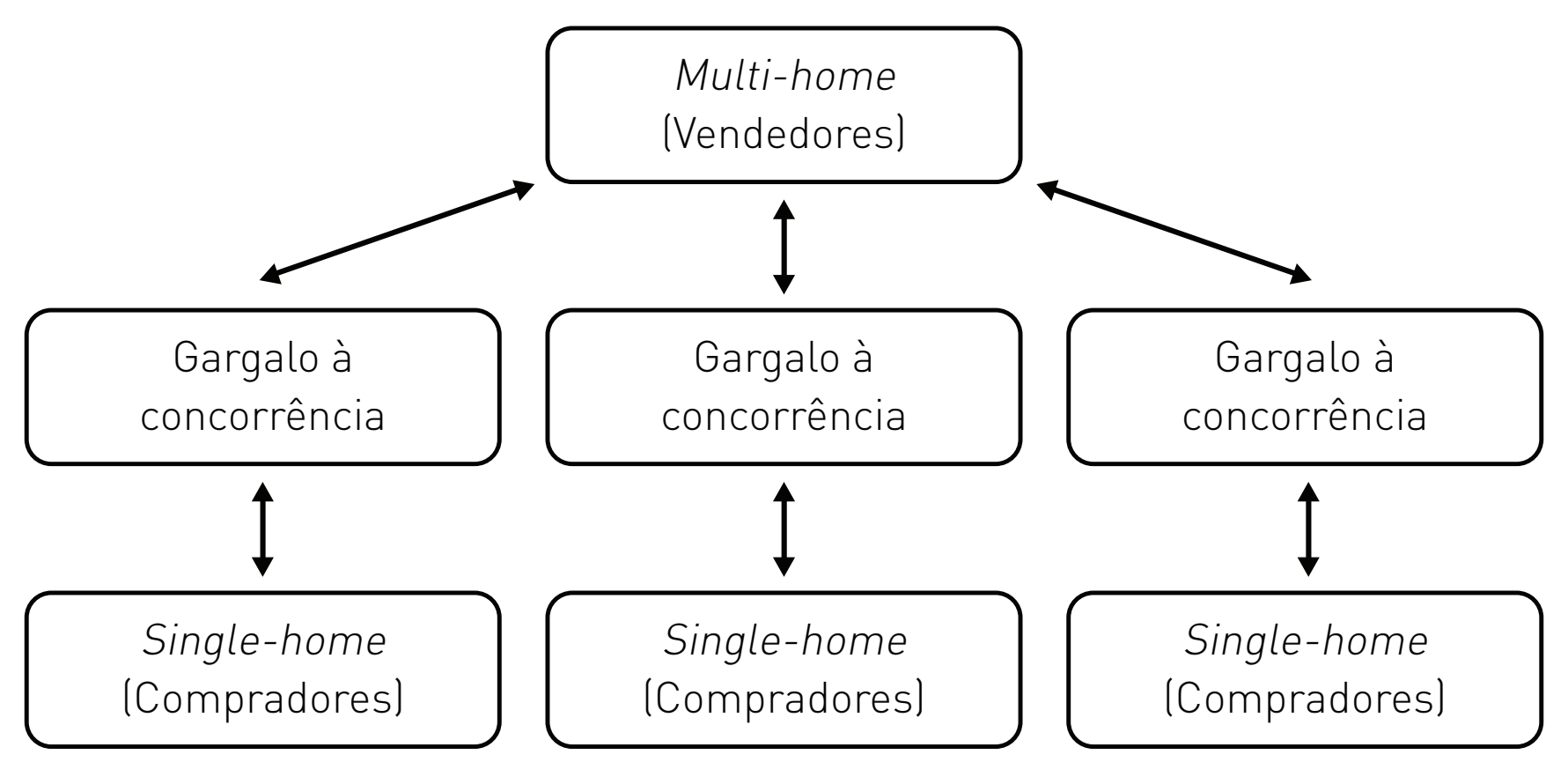

Fonte: Elaboração própria.

Nos termos de Armstrong (2006), as plataformas de dois lados com gargalos à concorrência teriam três características principais: (i) operam em mercados concentrados e que possuem algum poder de mercado, ainda que pela análise tradicional não tenham posição dominante; (ii) possuem alto nível de fidelidade dos compradores de um lado da plataforma (single-home); e (iii) são capazes de explorar o grupo do outro lado da plataforma (multi-home), pois os vendedores precisam de acesso à plataforma para alcançar os consumidores finais de maneira economicamente viável.

O próprio autor alude que sua teoria do gargalo à concorrência é análoga ao chamado "mixed equilibria" (CAILLAUD e JULLIEN, 2003). Esses autores argumentam que o grupo single-home é beneficiado pela plataforma quanto a preços, ao passo que se extrai ao máximo o lucro do grupo multi-home, com o que Armstrong concorda. Rochet e Tirole (2003) também possuem argumentação semelhante - mesmo que específica para o mercado de cartão de crédito, mas que pode ser aplicada de modo mais abrangente - no sentido de que é característica da teoria do gargalo à concorrência a verificação de que o grupo single-home é privilegiado, enquanto os interesses do grupo multi-home são ignorados em uma situação de equilíbrio (ARMSTRONG, 2006). Similarmente, Armstrong e Wright (2005) discorrem que, nesses casos de gargalo à concorrência, as plataformas competem agressivamente para atrair compradores (single-home). Estes, então, pagam pouco ou até mesmo nada para se 
registrarem à plataforma, e os lucros são advindos dos vendedores (multi-home), que, para acessarem tais compradores, precisam utilizar-se da plataforma. Grimes (2005) também denomina essa situação de gatekeeper power (FTC, 2001), em sintonia com as terminologias mencionadas por algumas autoridades antitruste estrangeiras. Certos mercados são identificados na literatura como gargalos à concorrência, entre eles jornais, agências de turismo $\left(\right.$ ARMSTRONG, 2006) ${ }^{20}$ e supermercados, como se passa a expor a seguir.

\subsection{SUPERMERCADO COMO “GARGALO À CONCORRÊNCIA" PARA CONSUMIDORES FINAIS E PARA FORNECEDORES}

Acadêmicos e autoridades de defesa da concorrência já destacaram a característica dos supermercados como gargalos à concorrência, utilizando para tanto a nomenclatura "competitive bottleneck" ou "gatekeepers". Entre os acadêmicos mencionam-se, por exemplo, Armstrong (2006), Savrin apud FTC (2000) ${ }^{21}$ e Berasategi (2014). Entre as autoridades antitruste estrangeiras citam-se, por exemplo, a Australian Competition and Consumer Commission (AUSTRÁliA, 2008), a Autoridade de Concorrência de Portugal (PORTUGAL, 2010), a Finnish Competition Authority (2012, p. 23) ${ }^{22}$ e o documento para discussão da UNCTAD (2014).

Similarmente à Figura 1, identifica-se da seguinte maneira o supermercado como um gargalo à concorrência (Figura 2):

20 As agências de turismo seriam competitive botllenecks, pois os agentes de turismo podem usar apenas um sistema aéreo de reserva (single-home), ao passo que as companhias aéreas são forçadas a transacionar com todas as plataformas possíveis para ter acesso aos clientes dos agentes de turismo (multi-home) (ARMSTRONG, 2006).

21 O autor, em evento organizado pela Federal Trade Commission, em 2000, mencionou a discussão do papel dos grandes varejistas como "gatekeepers", pelo papel exercido tanto com os fornecedores no lado do aprovisionamento quanto com os consumidores do lado da venda. Para essa análise, apontou - mencionando a discussão na União Europeia envolvendo o caso Kesko/Tuko na Finlândia - que do lado do aprovisionamento havia sido realizada análise a respeito da existência de alternativas apropriadas para os fornecedores para as suas vendas aos varejistas.

"It acts as a gatekeeper in managing shelfspace and selection and in deciding which products should be marketed"; "Private labels emphasize the role of the trade as a gatekeeper. The trade manages selection, pricing and display. The trade also obtains information on the cost structure of products through the private labels. Considering all these things it may be stated that private labels do not necessarily compete with branded products in a competition neutral way." 


\section{FIGURA 2 - SUPERMERCADO COMO GARGALO À CONCORRÊNCIA}

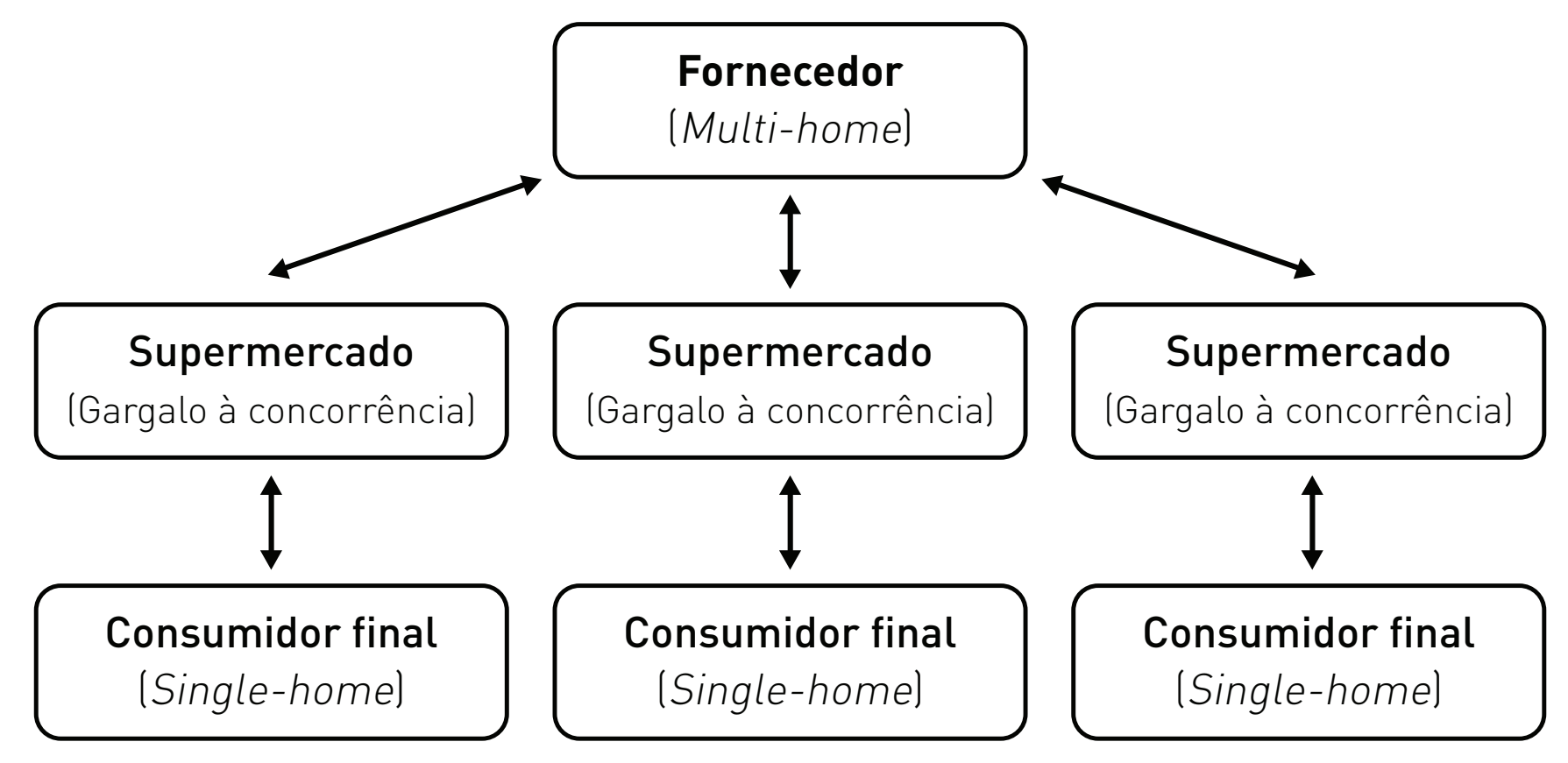

Fonte: Elaboração própria.

Propõe-se que os supermercados sejam analisados concorrencialmente como plataformas de dois lados com características de gargalo à concorrência, pois preenchem as três características fundamentais desse conceito. Primeiro porque (i) operam em mercados concentrados e possuem poder de mercado, ainda que pela análise tradicional não tenham posição dominante. Segundo porque (ii) têm alto nível de fidelidade dos consumidores de um lado da plataforma (single-home). E terceiro porque (iii) são capazes de explorar os grupos do outro lado da plataforma (multi-home), pois vendedores precisam de acesso a esta para alcançarem os consumidores finais de maneira economicamente viável.

Quanto ao (i) poder de mercado, os supermercados operam em mercado com histórico e tendência de consolidação, cujas práticas comerciais evidenciam o poder destes tanto nos mercados varejistas (venda) quanto nos de aprovisionamento (compra), ainda que pela análise tradicional não tenham posição dominante. A concentração é um importante poder de mercado dos varejistas, mesmo que os percentuais de participação de mercado individualmente considerados sejam abaixo dos níveis de dominância tradicionais.

Quanto à (ii) fidelidade dos consumidores de um lado da plataforma, tem-se que os consumidores finais tendem a visitar apenas um supermercado (single-home) e tê-lo como um gargalo por diversos fatores cumulados. Os consumidores tendem a se fidelizar a um único varejista por diversos fatores, entre eles: (i) pela restrição das opções de supermercados, tendo em vista a concentração econômica e as barreiras à entrada e à expansão nos mercados locais; (ii) pela redução da percepção sobre diferenças de preços, decorrente da transparência das condições de mercado e também da entrada das marcas próprias; (iii) pela crescente tomada 
de decisões dentro da loja do supermercado e diante das gôndolas, o que aumenta a influência das práticas comerciais implementadas pelo varejista; e (iv) pela crescente aceitação das marcas próprias pelos consumidores finais.

Ainda, quanto à (iii) capacidade de explorar o grupo do outro lado da plataforma, tem-se que os supermercados conseguem estrangular os fornecedores (multi-home) que desejam inserir seus produtos nas gôndolas dos supermercados. O modelo exitoso de one-stop shop faz que os fornecedores de produtos de marcas independentes não consigam alcançar os consumidores finais senão por meio da plataforma do supermercado. Uma vez acessada a plataforma, diversas variáveis importantes para a competitividade de um produto (como preço, apresentação e marketing) são controladas pelos supermercados dentro da loja, que podem influenciar os consumidores finais a favor das marcas próprias, em detrimento das marcas independentes do fornecedor. Em que pese isso, há o risco de retaliações, que deixa os fornecedores sem alternativas razoáveis para escoamento dos seus produtos senão pelos supermercados, em especial diante de um varejo on-line ainda incipiente (FRIEDERISZICK e GŁOWICKA, 2015).

Assim, sob a perspectiva dos fornecedores, Berasategi (2014) assevera que os produtos de marcas independentes precisam superar pelo menos duas dificuldades para alcançar sucesso no mercado: primeiro, o acesso aos supermercados, para em seguida passar ao segundo, que é a própria aceitação do produto pelos consumidores finais. O acesso a uma rede de distribuição é condição sine qua non para um negócio viável da indústria, para que, assim, possa alcançar um número suficiente de consumidores. A aceitação do produto pelos consumidores finais, porém, depende não apenas de suas características intrínsecas, mas também de diversas outras variáveis (como preço, apresentação e marketing), que são controladas pelos supermercados dentro da loja. Como já observado, esse mesmo supermercado é não apenas um simples comprador, mas sim um prestador de serviços para acesso à loja, com interesses possivelmente obtusos, em um cenário de marcas próprias. Assim, a superação de ambas as dificuldades depende do relacionamento dos fornecedores com os supermercados, o que dá a estes significativo poder e reforça seu papel de gargalo quase intransponível à concorrência entre produtos de marca. Bell (2009) alude que esse gargalo surge tanto em casos de novos produtos, que precisam de uma ampla rede de distribuição para serem capazes de alcançar os consumidores finais e crescer, quanto em casos de produtos existentes, quando qualquer perda repentina de acesso e/ou de vendas para um supermercado específico não é compensada por eventual aumento de vendas para outro supermercado, de modo que a rentabilidade é drasticamente reduzida.

Essa característica de gargalo à concorrência foi mencionada, por exemplo, no caso concreto da fusão entre as redes varejistas finlandesas Kesko/Tuko, analisada pela Comissão Europeia (1996). Nessa análise, foi utilizada a expressão “gatekeepers” para representar o poder único que os supermercados, em um cenário pós-operação de concentração econômica, deteriam no mercado. O anúncio da fusão entre as duas varejistas de alimentos da Finlândia 
foi realizado em maio de 1996, e, em novembro, a Comissão determinou sua reprovação. Em sua análise, apontou-se que a empresa resultante da fusão teria a habilidade de exercer seu poder de mercado para determinar a extensão do acesso que um fornecedor teria no mercado varejista e em quais termos esse acesso estaria disponível. Esse gatekeeper effect seria ainda maior diante da existência dos produtos de marca própria da Tuko, que poderiam ser utilizados como uma ferramenta de negociação em face dos fornecedores para conseguir concessões adicionais, o que poderia servir como uma barreira à entrada e permitiria à empresa adquirente Kesko atuar no mercado varejista sem preocupações com os demais concorrentes. A maioria dos fornecedores - com exceção de multinacionais, que têm marcas altamente reconhecidas dos seus produtos - estaria, então, dependente dos dois supermercados e não seria capaz de resistir ao poder de mercado das compradoras.

Na opinião de Curtin, Goldberg e Savrin (1998), o modo pelo qual a Comissão Europeia analisou essa fusão superou a maneira tradicional - voltada para a perspectiva dos consumidores e dos competidores - e alcançou um novo paradigma, voltado para a perspectiva dos fornecedores das empresas em concentração econômica.

Considerando tanto a doutrina acadêmica quanto a experiência antitruste internacional, propõe-se neste artigo que o supermercado é uma plataforma de dois lados com características de gargalo à concorrência, e que as tradicionais funções por ele exercidas não refletem toda a sua extensão de relações jurídicas, pelo que se passa a expor a seguir.

\section{AS RELAÇÕES JURÍDICAS DO VAREJO SUPERMERCADISTA}

No contexto de uma moderna análise antitruste que visualiza os supermercados como plataformas de dois lados com características de gargalo à concorrência, será proposto um novo modo de compreensão das possíveis relações jurídicas dos agentes no varejo supermercadista. Para além das tradicionais relações horizontais entre varejista e varejista (concorrentes) e fornecedor e fornecedor (concorrentes), e vertical entre varejista e fornecedor (comprador/prestador de serviços de acesso à plataforma), há também dois novos paradigmas "híbridos" meiro do supermercado concorrente dos seus fornecedores (detentor de marcas próprias),

23 Esse emaranhado "híbrido" de relações horizontais e verticais foi estudado por Lianos (2009, p. 99-124). "The competition assessment of hybrid commercial practices in distribution, such as dual distribution and private labels, unveils the conceptual weakness of the vertical/horizontal dichotomy and the risks of a formalistic approach in characterizing the restraints. The main reason for introducing this dichotomy was the shift towards an effects-based economic oriented approach. The labels, vertical and horizontal, do not, however, always correspond to clear presumptions of anti- or pro-competitive effects and are subject to manipulation. The risk is that competition authorities and courts focus on the vertical or horizontal character of the restriction, instead of examining the actual or potential anticompetitive 
e segundo do supermercado como fornecedor da indústria fornecedora (detentor do espaço nas gôndolas/prestador de serviços dentro da plataforma). Esses dois últimos paradigmas da relação vertical, por sua vez, podem também ter repercussões horizontais e diagonais. Esse emaranhado de relações jurídicas, possivelmente conflitantes, pode ser observado na Figura 3, a seguir.

FIGURA 3 - RELAÇÕES JURÍDICAS DO VAREJO SUPERMERCADISTA

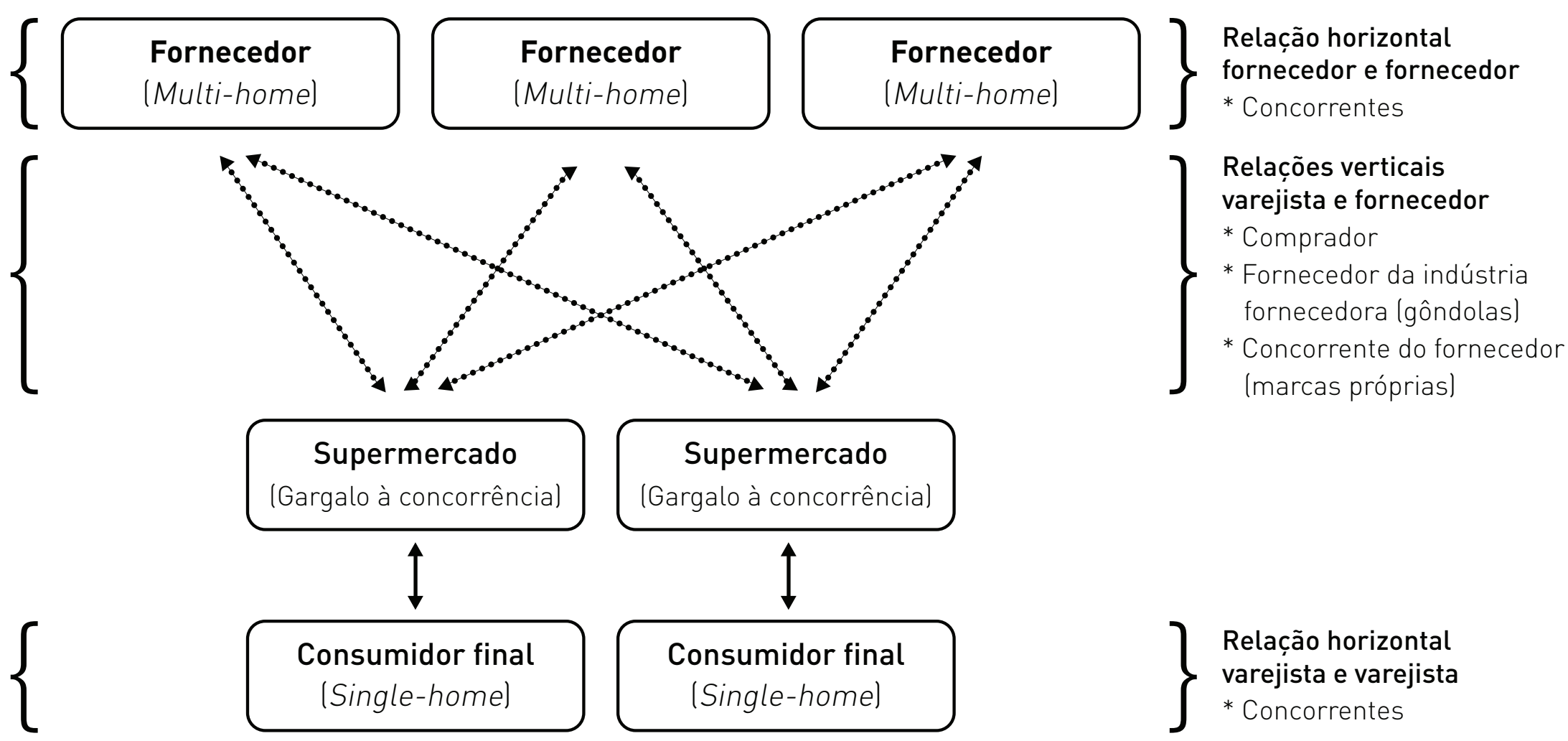

Fonte: Elaboração própria.

\section{I. AS RELAÇÕES JURÍDICAS DO VAREJO SUPERMERCADISTA NAS RELAÇÕES VERTICAIS}

Diversos acadêmicos, como Dobson (2005) e Gordilho Jr. (2012), e autoridades antitruste estrangeiras, como a Comissão Europeia (2010c), apontam no sentido de que os supermercados não podem mais ser vistos como meros compradores no mercado, nos termos da tradicional análise do varejo supermercadista. Em uma moderna visão do setor, considerando

effects and the economic context of the agreement". Outro autor que tratou do tema, especificamente sob a perspectiva da comunidade europeia, foi Gilo (2009, p. 140-160). 
o supermercado como plataforma de dois lados com características de gargalo à concorrência, observa-se que, nas relações verticais entre varejista e fornecedor, o supermercado possui a capacidade de exercer, individual ou conjuntamente, pelo menos três relações jurídicas: comprador / prestador de serviços de acesso à plataforma, fornecedor da indústria fornecedora/prestador de serviços dentro da plataforma e concorrente/detentor de marcas próprias. No exercício dessas três relações jurídicas, os objetivos do varejista podem não ser coincidentes - ou seja, podem ser conflitantes -, o que pode trazer questionamentos concorrenciais e reforça o papel não neutro desse agente no mercado. Essas três relações jurídicas do varejista com o fornecedor nas relações verticais serão detalhadas a seguir.

\section{I . I VAREJISTA COMO PRESTADOR DE SERVIÇOS AO FORNECEDOR PARA ACESSO À PLATAFORMA}

\section{(COMPRADOR DO FORNECEDOR)}

A primeira relação jurídica do varejista na relação vertical com os fornecedores é a mais comumente mencionada pela visão tradicional, do supermercado como comprador de produtos de marca independente do fornecedor. Considerando o novo paradigma dos supermercados como plataformas de dois lados com características de gargalo à concorrência, essa função dissocia-se apenas da sua visão como comprador e alia-se à visão do varejista como prestador de serviços para fornecedores e consumidores finais na plataforma. Isso significa que o supermercado não simplesmente compra o produto, embute sua margem de lucro e revende, como um simples revendedor. Ele, sob essa moderna visão, tem uma atuação mais abrangente, de prestador de serviços, autorizando ou não, em cada caso e a partir do cumprimento ou não de determinadas exigências, que produtos entrem em sua plataforma - ou seja, em suas lojas.

No exercício dessa primeira relação jurídica, o varejista implementa práticas comerciais verticais possivelmente questionáveis em termos concorrenciais, como as transferências de custos e de riscos, a alteração de cláusulas contratuais de modo retroativo e a influência nos fornecedores dos fornecedores.

\section{I . 2 VAREJISTA COMO PRESTADOR DE SERVIÇOS AO FORNECEDOR DENTRO DA PLATAFORMA}

(FORNECEDOR DA INDÚSTRIA FORNECEDORA)

Uma segunda relação jurídica do varejista na relação vertical com os fornecedores diz respeito à sua atuação ao comercializar espaços em gôndolas para a venda dos produtos de marca independente. O supermercado, ao ser o gargalo à concorrência que intermedeia consumidores finais e fornecedores, controla elementos essenciais para o sucesso de um produto (como preço, apresentação e marketing), e passa a ser um prestador de serviços dentro da plataforma, ou seja, dentro da loja.

No exercício dessa segunda relação jurídica, o varejista implementa práticas comerciais verticais possivelmente questionáveis em termos concorrenciais, genericamente denominadas pagamentos de taxas e condições de acesso ("access fees and terms") para espaço em gôndola, 
que incluem não apenas os efetivos pagamentos, mas também práticas como a gestão de categorias, relacionadas também ao modo de exposição dos produtos nas prateleiras de suas lojas ("planogram"). ${ }^{24}$

\section{I . 3. VAREJISTA COMO CONCORRENTE DO FORNECEDOR (CONCORRENTE DO FORNECEDOR)}

A terceira relação jurídica do varejista na relação vertical com os fornecedores surge com a criação das marcas próprias, por meio da qual os grandes supermercados se tornaram um dos concorrentes mais importantes da indústria fornecedora. O varejista deixa de ser um mero distribuidor de produtos aos consumidores e sua atuação como detentor de produtos de marcas próprias o leva, automaticamente, a ser concorrente dos fornecedores detentores de produtos de marca independente. Os incentivos do supermercado, portanto, evidenciam-se ainda mais conflitantes na medida em que, de uma relação verticial, passa-se a repercussões horizontais no mercado.

No exercício dessa terceira relação jurídica, o varejista implementa práticas comerciais verticais possivelmente questionáveis em termos concorrenciais, como aquelas que alteram a dinâmica de acesso à e dentro da plataforma aos fornecedores concorrentes das marcas próprias.

\subsection{AS RELAÇõeS JURÍDICAS DO VAREJO SUPERMERCADISTA NAS RELAÇÕES HORIZONTAIS}

Além das relações verticais entre varejista e fornecedor, existem no varejo supermercadista as tradicionais relações horizontais entre os agentes econômicos no mercado, que serão abordadas a seguir.

\subsection{VAREJISTA CONCORRENTE DO VAREJISTA}

Uma quarta relação jurídica, na relação horizontal no mercado de varejista (venda), diz respeito ao fato de os supermercados se encontrarem em posição de concorrência horizontal com os demais supermercados. Nesse exercício, os varejistas são capazes de implementar práticas que podem prejudicar a concorrência horizontal.

\subsubsection{FORNECEDOR CONCORRENTE DO FORNECEDOR}

Uma quinta relação jurídica, na relação horizontal no mercado de aprovisionamento (compra), diz respeito aos fornecedores que se encontram em posição de concorrência horizontal com os demais fornecedores. A visão antitruste tradicional centra suas preocupações nessa área, considerando as eventuais restrições impostas pelos fabricantes no mercado em termos

24 Por "planogram" entende-se a representação gráfica do layout dos produtos de uma categoria em determinada área (gôndola) da loja (ESPANHA, 2011, p. 93). Ademais, pode ser entendida como a diagramação ilustrativa da localização dos produtos nas gôndolas do varejista, a quantidade de espaço em que o produto será alocado e quantas faces/exposições cada produto vai ter na ilha da categoria (AUSTRÁLIA, 2008, p. 337). 
de oferta no mercado. ${ }^{25}$ No exercício dessa quinta relação jurídica os fornecedores são capazes de implementar práticas que podem prejudicar a concorrência horizontal.

\section{CONCLUSÃO}

A proposta de uma moderna análise antitruste do varejo supermercadista contempla os supermercados como plataformas de dois lados com características de gargalo à concorrência. Ao adotar essa nova visão, supera-se a análise tradicional segundo a qual os supermercados seriam agentes neutros no mercado que simplesmente transmitiriam a demanda dos consumidores para os fornecedores, com resultados nulos ou positivos para o mercado, privilegiando-se, portanto, os resultados dinâmicos no mercado de médio e longo prazo, especialmente em um mercado tão afeto ao consumidor, que atende às demandas mais básicas, como alimentação (produtos não duráveis) e bens (produtos duráveis).

Conforme a teoria do "two-sided platforms", plataformas de dois lados possuem três características fundamentais: (i) a existência de dois grupos distintos que precisam um do outro de alguma maneira e que confiam na plataforma para intermediar as transações entre eles; (ii) a existência de externalidades indiretas entre os grupos de consumidores; e (iii) a não neutralidade da estrutura de preço. Por sua vez, essas plataformas de dois lados se configuram como gargalos à concorrência se: (iv) operam em mercados concentrados e que possuem algum poder de mercado, ainda que pela análise tradicional não tenham posição dominante; (v) possuem alto nível de fidelidade/lock in dos consumidores de um lado da plataforma (single-home); e (vi) são capazes de explorar o grupo do outro lado da plataforma (multi-home), pois esses vendedores precisam de acesso à plataforma para alcançar os consumidores finais de maneira economicamente viável.

A evolução da análise antitruste do varejo supermercadista se imbui do novo paradigma dos supermercados como plataformas de dois lados. De um lado da plataforma, o supermercado presta serviços de one-stop shopping aos consumidores finais. Do outro, o supermercado também presta serviços de acesso à e dentro da loja aos fornecedores. A existência desses dois grupos distintos que precisam um do outro e que confiam na plataforma do supermercado para intermediar as transações entre eles marca uma das características fundamentais da plataforma de dois lados. Outro ponto marcante dessa plataforma dos supermercados é a

25 Borghesani, Cruz e Berry (1998) apontam que, historicamente, as preocupações concorrenciais se concentravam nas discrepâncias causadas pelos fabricantes no mercado ("manufacturer push market"). Porém, de maneira crescente, estar-se-ia observando que a mudança de poder está tendendo sua balança para os varejistas (“consumer pull market"). Advertem, no entanto, que as políticas antitruste e seus casos julgados, no entanto, refletiriam apenas o poder dos fabricantes, sem se atentar para essa alteração no jogo de poder. 
existência de externalidades indiretas entre os dois grupos, uma vez que o valor dos supermercados para os consumidores finais aumenta o seu valor para os fornecedores, e vice-versa. Quanto à característica da não neutralidade da estrutura de preço das plataformas de dois lados, foi possível notar que os supermercados alteram a estrutura de preços dos fornecedores aos consumidores finais e não são agentes neutros nesse mercado.

Os supermercados, como plataformas de dois lados, também têm características de gargalo à concorrência ("gatekeepers"). Estão em mercados concentrados, têm alto nível de fidelidade/lock in dos consumidores finais (single-home) e são capazes de explorar os fornecedores (multi-home).

Nesse contexto, propõe-se um novo modo de compreensão das possíveis relações jurídicas dos agentes no varejo supermercadista. Para além das tradicionais relações horizontais entre varejista e varejista (concorrentes) e fornecedor e fornecedor (concorrentes), e vertical entre varejista e fornecedor (comprador/prestador de serviços de acesso à plataforma), há também dois novos paradigmas "híbridos" de relação vertical entre varejista e fornecedor que são pouco mencionados: primeiro, o paradigma do supermercado concorrente dos seus fornecedores (detentor de marcas próprias), e, segundo, o do supermercado como fornecedor da indústria fornecedora (detentor do espaço nas gôndolas/prestador de serviços dentro da plataforma). A partir da compreensão desses novos paradigmas, o direito da concorrência pode desenvolver novas ferramentas e, assim, alcançar melhores resultados para garantir a concorrência qualitativa e, ao fim e ao cabo, a justiça social, fins constitucionais atribuídos a esse ramo do direito.

\section{AGRADECIMENTOS}

A autora agradece à contribuição da pesquisadora Nayara Mendonça na revisão final deste artigo.

\section{REFERÊNCIAS}

ARMSTRONG, Mark. Competition in two-sided markets. RAND Journal of Economics, v. 37, n. 3, p. 668 -691, Autumn 2006.

ARMSTRONG, Mark. Two-sided markets: economic theory and policy implications. In: CHOI, Jay Pil (ed.). Recent developments in antitrust: theory and evidence. Cambridge: The MIT Press, 2007. p. 39-59. 
ARMSTRONG, Mark; WRIGHT, Julian. Two-sided markets, competitive bottlenecks and exclusive contracts. Economic Theory, v. 32, p. 353-380, 2007.

ATHAYDE, Amanda. Antitruste, varejo e infrações à ordem econômica. São Paulo: Singular, 2017.

AUSTRÁLIA. AUSTRALIAN COMPETITION AND CONSUMER COMMISSION. Inquiry into the competitiveness of retail prices for standard groceries, July 2008. Disponível em: https: / /www.accc.gov.au/ publications/report-of-the-accc-inquiry-into-the-competitiveness-of-retail-prices-for-standard-groceriesjuly-2008. Acesso em: 11 nov. 2019.

BASKER, Emek; NOEL, Michael. Competition challenges in the supermarket sector with an application to Latin American markets. Centro Regional de Competência para América Latina (CRCAL), 2013.

BELL, Dick. The business model for manufacturers' brands. Private label, brands and competition policy: The changing landscape of retail competition. Oxford: Ariel Ezrachi and Ulf Bernitz, 2009.

BERARDO, José C. M.; BECKER, Bruno Bastos. Brazil. In: KOBEL, Pierre; KËLLEZI, Pranvera; KILPATRICK, Bruce (eds.). Antitrust in the groceries sector \&liability issues in relation to corporate social responsibility. Springer, 2015.

BERASATEGI, Javier. Supermarket power: serving consumers or harming competition, 2014. Disponível em: http: / / www.supermarketpower.eu/documents/38179/39950/Supermarket+Power.pdf. Acesso em: 25 nov. 2019.

BORGHESANI JR., William H.; CRUZ, Peter L. de La; BERRY, David. Food for thought: the emergence of power buyers and its challenge to competition analysis. Stan. JL Bus. \& Fin., v. 4, p. 40-43, 1998.

BRASIL. CONSELHO ADMINISTRATIVO DE DEFESA ECONÔMICA (CADE). Portaria Conjunta SEAE/SDE n. 50, de 1 de agosto de 2001. Aprova o Guia para Análise Econômica de Atos de Concentração Horizontal. Disponível em: http://www.cade.gov.br/assuntos/normas-e-legislacao/ portarias /2001portariaconjunta50-1_guia_para_analise_economica_de_atos_de_concentracao.pdf/ view. Acesso em: 22 nov. 2019.

BRASIL. CONSELHO ADMINISTRATIVO DE DEFESA ECONÔMICA (CADE). Guia de análise dos atos de concentração horizontal, 2016.

CAILlAUD, Bernard; JULLIEN, Bruno. Competing cybermediaries. European Economic Review, v. 45, n. 4, p. 797-808, 2001. 
CAILlAUD, Bernard; JULLIEN, Bruno. Chicken \& egg: competition among intermediation service providers. RAND Journal of Economics, v. 34, n. 2, p. 309-328, Summer 2003.

COMISSÃO EUROPEIA. Commission Decision of 20 November 1996 declaring a concentration to be incompatible with the common market (Case No IV/M.784 - Kesko/Tuko). 1996. Disponível em: https:/ / op. europa. eu/en/publication-detail/-/publication/804cedcb-965e-43c6-bcc7-be69b8cd24cc. Acesso em: 28 nov. 2019.

COMISSÃO EUROPEIA. Buyer power and its impact on competition in the food retail distribution sector of the European Union. 1999. Disponível em: https://op.europa.eu/en/publication-detail/ - / publication/ 608e17ad-44a5-4a36-91cb-87d59bcbd1df. Acesso em: 28 nov. 2019.

COMISSÃO EUROPEIA. Comunicação da Comissão - Orientações relativas à aplicação do n. 3 do artigo 81. ${ }^{\circ}$ do Tratado (Texto relevante para efeitos do EEE). par. 84. 2004. Disponível em: https: //eurlex.europa.eu/legal-content/PT/TXT/HTML/?uri=CELEX:52004XC0427(07)\&from=EN. Acesso em: $1^{\circ}$ dez. 2019.

COMISSÃO EUROPEIA. Regulation 717/2007 of the European Parliament and of the Council of 27 June 2007, on public mobile telephone networks within the Community and amending Directive $2002 / 21 /$ EC.

COMISSÃO EUROPEIA. The impact of private labels on the competitiveness of the European food supply chain, 2010a. p. 160. Disponível em: https:// ec.europa.eu/growth/content/impact-private-labelscompetitiveness-european-food-supply-chain-0_en. Acesso em: 28 nov. 2019.

COMISSÃO EUROPEIA. Antitrust: Commission probes allegations of antitrust violations by Google, IP/10/1624, 30.11.2010, 2010b. Disponível em: https: / / ec. europa.eu/commission/presscorner/ detail/en/IP_10_1624. Acesso em: 25 nov. 2019.

COMISSÃO EUROPEIA. Commission StaffWorking Document on Retail Services in the Internal Market, 2010c. Disponível em: http: / / ec.europa.eu/DocsRoom/documents/14557/attachments/1/translations. Acesso em: 22 nov. 2019.

COMISSÃO EUROPEIA. Regulation 531 /2012 of the European Parliament and of the Council of 13 June 2012, on roaming on public mobile communication networks within the Union.

COMISSÃO EUROPEIA. Antitrust: Commission seeks feedbacks on commitments offered by Google to address competition concerns, IP/13/371, 25.04.2013. 2013a. Disponível em: https: / / ec.europa.eu/ commission/presscorner/detail/en/IP_13_371. Acesso em: 25 nov. 2019. 
COMISSÃO EUROPEIA. Green Paper, “Towards an integrated European market for card, internet and mobile payments", COM/2011/0941 final, 11.01.2012, Proposal for a Regulation of the European Parliament and of the Council on interchange fees for card-based payment transactions, COM/2013/ 5503, 24.07.2013, 2013b.

CURTIN JR., John J.; GOLDBERG, Daniel L.; SAVRIN, Daniel S. EC's rejection of the Kesko/Tuko merger: Leading the way to the application of a gatekeeper analysis of retailer market power under US antitrust laws. Boston College Law Review United States, v. 40, p. 537, 1998.

DOBSON, Paul. Exploiting buyer power: lessons from the British grocery trade. Antitrust Law Journal, v. 72, p. 529-562, 2005.

ESPANHA. COMISIÓN NACIONAL DE LA COMPETENCIA. Report on the relations between manufacturers and retailers in the food sector, 2011. p. 93.

ESTADOS UNIDOS. Federal Communications Commission Report and Order. Preserving the Open Internet, Broadband Industry Practices, 10-201, 23.12.2010.

EUROPA. Council Regulation 2299/1989, de 24.07.1989, subsequentemente emendada pelas Regulations 3089/1993 e 323/1999. Essa regulamentação setorial foi recentemente revogada pela Regulation 80/2009 of the European Parliament and of the Council of 14 January 2009 on a Code of Conduct for computerized reservation systems.

EUROPA. EUROPEAN PARLIAMENT. Resolution of 17 November 2011 on the open internet and net neutrality in Europe, P7_TA-PROV(2011)0511 and Connected Continent legislative package.

EVANS, David S. Some empirical aspects of multi-sided platform industries. Review of Network Economics, v. 2, n. 3, 2003a.

EVANS, David S. The antitrust economics of multi-sided platforms markets. Yale Journal of Regulation, v. 20, n. 2, p. 325-381, 2003b.

EVANS, David S.; SCHMALENSEE, Richard. Matchmakers: The new economics of multisided platforms. Harvard: Harvard Business Review Press, 2016.

EVANS, David S.; SCHMALENSEE, Richard. Markets with two-sided platforms. Issues in Competition Law And Policy 667, ABA Section of Antitrust Law, v. 1, cap. 28, 1 out. 2008. Disponível em: https: / / ssrn.com/abstract=1094820. Acesso em: 11 nov. 2019. 
FEDERAL TRADE COMMISSION (FTC). Workshop on slotting allowances and other marketing practices in the grocery industry. 2001. Disponível em: https://www.cov.com/-/media/files/corporate/publications/ 2001/02/oid6137.doc. Acesso em: 25 nov. 2019.

FEDERAL TRADE COMMISSION (FTC). Workshop on slotting allowances and other grocery marketing practices, 2000. p. 386-387. Disponível em: https://www.ftc.gov/news-events/events-calendar/ 2000/05/workshop-slotting-allowances-other-grocery-marketing-practices. Acesso em: 28 nov. 2019.

FILISTRUCCHI, Lapo; GERADIN, Damien;VAN DAMME, Eric. Identifying two-sided markets. Londres: TILEC Discussion Paper n. 2012-008, 2012.

FINNISH COMPETITION AUTHORITY. Study on trade in groceries - How does buyer power affect the relations between trade and industry? 2012. Disponível em: https://www.kkv.fi/globalassets/kkvsuomi/julkaisut/selvitykset/2012/en/fca-reports-1-2012-study-on-trade-in-groceries.pdf. Acesso em: 28 nov. 2019.

FORGIONI, Paula A. Contrato de distribuição. 2. ed. São Paulo: Revista dos Tribunais, 2008.

FRIEDERISZICK, Hans W.; GŁOWICKA, Ela. Competition policy in modern retail markets. Journal of Antitrust Enforcement, 2015.

GALBRAITH, John Kenneth. American capitalism: The concept of countervailing power. v. 619. Transaction Publishers, 1970.

GILO, David. Private labels, dual distribution, and vertical restraints - An analysis of the competitive effects. In: EZRACHI, Ariel; BERNITZ, Ulf (eds.). Private labels, brands and competition policy: The challenging landscape of retail competition. Oxford: Oxford Press, 2009.

GORDILHO JR., Mário Sérgio Rocha. Análise de poder de compra no mercado de varejo de bens duráveis - desafios para o novo Cade. Boletim Latino-Americano de Concorrência, n. 31, p. 51, abr. 2012.

GRIMES, Warren S. Buyer power and retail gatekeeper power: protecting competition and atomistic seller. Antitrust Law Journal, v. 72, n. 2, 2005.

HAGIU, Andrei. Merchant or two-sided platform? Review of Network Economics, v. 6, n. 2, 2007.

KIRKWOOD, John B. Buyer power and merger policy. Seattle University School of Law. Working Paper, Draft 1, 1 April 2011. 
LIANOS, Ioannis. The vertical/horizontal dichotomy in competition law: some reflections with regard to dual distribution and private labels. In: EZRACHI, Ariel; BERNITZ, Ulf (eds.). Private labels, brands and competition Policy: the challenging landscape of retail competition. Oxford: Oxford Press, 2009. p. 99-124.

LIM, Youngsik. Market definition/market power in two-sided markets. ICN Webinar, 08.10.2015.

LLANES, Gastón; RUIZ-ALISEDA, Francisco. Private contracts in two-sided markets. NET Institute Working Paper, n. 15-16, 1 out. 2015. Disponível em: https://papers.ssrn.com/sol3/papers.cfm?abstract_id= 2675508. Acesso em: 11 nov. 2019.

MAITLAND-WALKER, Julian. Buyer power. European Competition Law Review, v. 21. n. 3, p. 170, mar. 2000.

MILLS, Gordon. Buyer power of supermarkets. Agenda:A Journal of Policy Analysis and Reform, v. 10, n. 2, p. 145-162, 2003.

ORGANIZAÇÃO PARA A COOPERAÇÃO E DESENVOLVIMENTO ECONÔMICO (OCDE). Roundtable on two-sided markets. Competition Committee, DAF/COMP, (2009)69, 2009. Background note by Daniel EVANS.

ORGANIZAÇÃO PARA A COOPERAÇÃO E DESENVOLVIMENTO ECONÔMICO (OCDE). Network effects and efficiencies in multisided markets - Note by H. Shelanski, S. Knox and A. Dhilla. Hearing on re-thinking the use of traditional antitrust enforcement tools in multi-sided markets. Competition Committee, DAF/COMP/WD(2017)40, 2017.

ORGANIZAÇÃO PARA A COOPERAÇÃO E DESENVOLVIMENTO ECONÔMICO (OCDE). Rethinking Antitrust Tools for Multi-Sided Platforms, 2018. p. 190-198.

PARKER, Geoffrey G.; VAN ALSTYNE, Marshall W. Two-sided network effects: A theory of information product design. Management Science, v. 51, n. 10, p. 1.494-1.504, 2005.

PORTUGAL. AUTORIDADE DE CONCORRÊNCIA DE PORTUGAL. Relatório Final sobre Relações Comerciais entre a Distribuição Alimentar e os seus Fornecedores, 2010. Disponível em: http: //www. concorrencia.pt/SiteCollectionDocuments/Estudos_e_Publicacoes/Outros/AdC_Relatorio_Final_D istribuicao_Fornecedores_Outubro_2010.pdf. Acesso em: 11 nov. 2019.

RAGAZZO, Carlos Emmanuel Joppert; MACHADO, Kenys Menezes. O CADE e o poder de compra no setor agropecuário. Economic Analysis of Law Review, v. 4, n. 2, p. 295-314, jul./dez. 2013. 
RICHARDS, Timothy; HAMILTON, Stephen F. Network externalities in supermarket retailing. Working Paper, 2007.

RICHARDS, Timothy; HAMILTON, Stephen F. Network externalities in supermarket retailing. European Review of Agricultural Economics, p. 11, 2012.

ROCHET, Jean-Charles; TIROLE, Jean. Cooperation among competitors: Some economics of payment card associations. The Rand Journal of Economics, v. 33, n. 4, p. 549-570, 2002.

ROCHET, Jean-Charles; TIROLE, Jean. Platform competition in two-sided markets. Journal of the European Economic Association, v. 1, n. 4, p. 990-1.029, 2003.

ROCHET, Jean-Charles;TIROLE, Jean. Defining two-sided markets. Mimeo, IDEI, Toulouse, France, jan. 2004.

ROCHET, Jean-Charles; TIROLE, Jean. Two-sided markets: a progress report. RAND Journal of Economics, RAND Corporation, v. 37, n. 3, p. 645-667, 2006.

RYSMAN, Marc. The economics of two-sided markets. The Journal of Economic Perspectives, v. 23, n. 3, p. $125-143,2009$.

SPECTOR, David. Addressing buyer power in merger control. Concurrences Review n. 3, art. n. 20.372, p. 34-39, September 2008 .

SULLIVAN, Lawrence A.; GRIMES, Warren S. The law of antitrust: An integrated handbook. St. Paul, MN: West Publishing, 2006.

TRIBUNAL VASCO DE DEFENSA DE LA COMPETENCIA. Distribution of daily consumer goods: competition, oligopoly and tacit collusion, 2009.

UNITED NATIONS CONFERENCE ONTRADE AND DEVELOPMENT (UNCTAD). Competition issues in the food chain: Possible measures to address buyer power in the retail sector, 2014. p. 1-10. Disponível em: http://unctad.org/meetings/en/Contribution/tdb61_c01_UNCTAD.pdf. Acesso em: 11 nov. 2019.

VIANNINI, Stefano. Bargaining and two-sided markets: the case of Global Distribution Systems (GDS) in Travelport's acquisition of Worldspan. Competition Policy Newsletter, n. 2, 2008.

WEYL, Glen. Monopolies in two-sided markets: comparative statics and identification. Department of Economics, Institute for Business and Economic Research, UC Berkeley, Department of Economics, Working Paper Series, 1 January 2008. 
WHITNEY, Simon. Errors in the concept of countervailing power. The Journal of Business of the University of Chicago, v. 26, n. 4, p. 238-253, 1953.

WRIGHT, Julian. One-sided logic in two-sided markets. Review of Network Economics, v. 3, n. 1, 2004.

\section{COMO CITAR ESTE ARTIGO:}

ATHAYDE, Amanda. Direito da concorrência e supermercados: como essas plataformas de dois lados podem trazer riscos aos consumidores? Revista Direito GV, v. 16, n. 1, jan./abr. 2020, e1940. doi: http://dx.doi.org/ 10.1590/2317-6172201940.

\section{Amanda Athayde}

Professora Doutora Adjunta de Direito Empresarial na UnIVERSIDADE DE BRASílIA (UNB) E DE DiREITO ECONÔMICO E da Concorrência no Instituto de Direito Público Brasiliense (IDP). DOUTORA EM DiREITO COMERCIAL PELA Universidade de São PaUlo (USP), Bacharel em DiReito PELA Universidade Federal de Minas Gerais (UFMG) e EM AdMINISTRAÇÃO DE EMPRESAS COM HABILITAÇÃO EM COMÉRCIO

Exterior pelo Centro Universitário UNA. Fol aluna da Université Paris I - Panthéon Sorbonne. Servidora Pública da CARREIRA de ANALISTA de COMÉRCIO Exterior. Atualmente, é Subsecretária de Defesa Comercial e Interesse Público do Ministério da Economia.

profa.amanda.athaydelagmail.com 